\title{
Technical Efficiency Analysis of Millet Production in the Sahel Region of Burkina Faso
}

\author{
Windinkonté SEOGO1, W. Jean-Pierre SAWADOGO² \\ ${ }^{1}$ Centre Universitaire Polytechnique de Kaya (CUPK), Université Joseph KI-ZERBO, Burkina Faso \\ 2 Université Thomas SANKARA, Ouagadougou, Burkina Faso \\ seogoaubin2@gmail.com, jeanpi.sawadogo@yahoo.fr
}

\begin{abstract}
Millet is the basic cereal crop which contributes to rural households' food security in the Sahel region of Burkina Faso. This study assesses the technical efficiency and its determinants of millet farmers in this region. A stochastic frontier approach is followed to analyze data collected on 106 households randomly selected in 2017. The mean technical efficiency is estimated at $71.23 \%$ implying that millet production may be increased by $28.77 \%$ with the same resources used by farmers. The results show that formal education, off farm income, breeding, and access to credit are the main factors affecting the production efficiency. The study recommends decisions makers to take appropriate measures regarding these factors, to enhance millet productivity in the Sahel region.
\end{abstract}

Keywords: Millet, Technical Efficiency, Stochastic Frontier Approach, Sahel Region, Burkina Faso.

\section{Introduction}

In Burkina Faso, agriculture plays an important role in the socio-economic development. The agricultural sector employs over $70 \%$ of the labor force and accounts for about $34 \%$ of the GDP (Coulibaly \& Savadogo, 2019). The basic crops grown are cereals which contribute to approximately $60 \%$ of households food needs (FAO, 2013). Sorghum, millet and maize are the three main crops that provide food security for rural people. Increasing cereal production is therefore one of the priority objectives of Burkina Faso authorities. After the 2008 food crisis, emergency measures were taken to increase yields and agricultural production. Among these measures is notably the promotion of the use of improved seeds, fertilizers, suitable agricultural equipment as well as the popularization of good agricultural practices. Despite these measures, agricultural productivity remains very low (Coulibaly \& Savadogo, 2019) and Burkina Faso still experiences food crisis situations, especially in arid areas like the Sahel region where rainfall is very low and variable. Three agro ecological zones exist in Burkina Faso: the sahelian zone, the sudano-sahelian zone and the pre-guinean zone.

The sahelian zone is the least wet area (less than $600 \mathrm{~mm}$ of rainfalls per year), the sudano-sahelian zone is moderately watered (between 600 to $900 \mathrm{~mm}$ of rainfalls per year) and the pre-guinean zone is the potential zone for agriculture with more than $900 \mathrm{~mm}$ of rainfalls per year. Due to poor soils and uncertain rainfalls in the Sahelian zone, millet is the most adapted food crop to be grown in this area. It represents around $70 \%$ of the total cereal production on average per year and contributes significantly to the food security of people living in this zone. Despite this importance, millet production remains fluctuating over time and below expectations. Rural populations frequently experience food insecurity. In 2012, the Sahel region as well as other regions of the country was confronted with the second food crisis in 3 years (FAO, 2019). Beyond the climatic conditions, the lowness of millet productivity in the region raises questions about the efficiency with which resources are used by farmers. For Keane et al. (2009), it is generally known that producers in most developing countries are operating under their potential production.

The high level of inefficiency that farmers face highlights that innovation and technology adoption are not the only constrains for agriculture development in those countries (Chavas et al., 2005). Thus, Brümmer (2006) argued that the reduction of inefficiency in agricultural production is a key factor in policies aiming at both reaching food security and reducing poverty in developing countries. In the specific case of Burkina Faso, it is found that technical efficiency contributes to poverty reduction (Noufé, 2020). It is thus very important to address issues related to production efficiency in the agricultural sector. The overall objective of this paper is to identify factors affecting millet farmers' technical efficiency in the Sahel region of Burkina Faso. It specifically assesses the level of millet farmers' technical efficiency and identifies the key factors affecting their technical efficiency. A number of studies have addressed the technical inefficiency of cereals farmers in Burkina Faso. Kaboré (2007) estimated rice farmers' technical efficiency at 83\% in the valley of Kou and at $76 \%$ in the valley of Bagré. Wouterse (2008) showed that both intercontinental migration and education 
increase efficiency in cereals production. Combary (2016) estimated the level of farmers' allocative efficiency at $35.8 \%$.

However, none of the previous studies has focused on the Sahel region where millet is the most important cereal, crop assuring rural people food security. Due to the low productivity of millet inducing food insecurity in the region, it is very important to highlight factors which hamper millet production. The results from our analysis may thus contribute to take appropriate measures to stimulate production efficiency and strengthen rural people food security in this region. The rest of the paper is structured as follows. Section 2 presents the review of literature. Section 3 is devoted to the methodology. Section 4 discusses the estimated results and section 5 concludes the paper and draws consistent policy implications.

\section{Literature Review}

Common Methods of Technical Efficiency Analysis: Common methods used to analyze production efficiency are Data Envelopment Analysis (DEA), Mamlquist Index and Stochastic Frontier analysis (SFA). Even if DEA and SFA are widely used, SFA which is a parametric method specifying the production as function of inputs and two error terms (common error term and the inefficiency component) is well indicated to analyze production efficiency in developing countries like Burkina Faso (Thiam et al., 2001; Njeru, 2010; Ogundari \& Awokuse, 2016). Many factors like climatic conditions may affect agricultural production. So, the assumption that all deviation from the frontier is due to inefficiency in DEA method is unrealistic. Moreover SFA has the advantage of allowing inferential statistics. This study therefore follows a stochastic frontier approach.

The Stochastic Frontier Approach: Farrell (1957) argued that the traditional neoclassical assumption that all firms are assumed to be fully efficient is unrealistic because in reality, some firms are more efficient than others. Efficiency means that the maximum output is reached with the minimum input. So, a production unit is considered as relatively inefficient if another one uses an inferior or equal amount of inputs to produce the same or more level of output. A weakness of Farrell (1957) frontier approach is the consideration of the inefficiency component as deterministic like in non-parametric methods. The stochastic frontier has been introduced as an improvement of Farrell (1957) frontier approach by Aigner et al. (1977) followed by Meeusen \& Van den Broeck, (1977). In this method, any deviation from the frontier is explained by two components: the error term and the inefficiency component.

The production frontier is expressed as follow:

$Y_{i}=f\left(X_{i j} ; \beta\right) e^{\left(\emptyset_{i}-\eta_{i}\right)}$

$\emptyset_{i}-\eta_{i}=u_{i} ; i=1, \ldots N ; \quad j=1, \ldots . . J$

$Y_{i}$ is the quantity of output generated by production unit $i ; X_{i j}$ a vector of inputs and $\beta$ a vector of parameters to be estimated. $\mathrm{N}$ is the number of production units and $\mathrm{J}$ the number of inputs. Specifying a translog production function and applying logarithm to equation (1) yields:

$\ln Y_{i}=\beta_{0}+\sum_{j=1}^{J} \beta_{j} X_{i j}+\sum_{j=1}^{J} \sum_{k=1}^{J} \beta_{j k} X_{i j} X_{i k}+\left(\emptyset_{i}-\eta_{i}\right), \quad \emptyset_{i_{i}}-\eta_{i}=u_{i}$

$\emptyset_{i_{i}}$ is the common random error term. It is symmetrically distributed of zero mean and constant variance $\sigma_{\square}^{2}$ and captures statistical noise or measurement error. $\eta_{i}$ represents the asymmetric error term assumed to be independently and identically distributed $\left(\eta_{i} \sim N\left(\mu, \sigma_{\eta}^{2}\right)\right)$. The equation explaining the technical inefficiency component $\eta_{i}$ is specified as follow:

$\eta_{i}=\delta Z_{i j}+W_{i}$

$Z_{i j}$ is a vector of factors affecting the technical inefficiency, $\delta$ a vector of parameters to be estimated and $W_{i}$ a random variable distributed as truncation of normal distribution of zero mean and variance $\sigma_{\eta}^{2}$ (Coelli, 1995).

Aigner et al. (1977) parameterized the variances of the model as follows: 
$\sigma^{2}=\sigma_{\Phi_{i}}^{2}+\sigma_{\eta}^{2}$ and $\gamma=\sigma_{\eta}^{2} / \sigma_{u}^{2}$ with $0<\gamma<1 . \gamma=0$ means all deviations from the frontier are fully explained by the error term and $\gamma=1$ implies all deviations from the frontier are due to the technical inefficiency.

The technical efficiency $\left(T E_{i}\right)$ of production unit $i$ is defined as the ratio between the observed output $\left(Y_{i}\right)$ and the frontier output $\left(Y_{i}^{*}\right)$ for a given amount of inputs used:

$T E_{i}=\frac{Y_{i}}{Y_{i}^{*}}=\frac{f\left(X_{i j} ; \beta\right) e^{\left(\emptyset_{i}-\eta_{i}\right)}}{f\left(X_{i j} ; \beta\right) e^{\left(\emptyset_{i i}\right)}}=e^{\left(-\eta_{i}\right)}$

Equations (4) and (3) are simultaneously estimated. The one step estimation technique is recommended as it yields consistent estimates (Coelli, 1995, Chiona et al., 2014).

\section{Methodology}

Empirical Model: We specify a translog function as follows:

$\ln Y_{i}=\beta_{0}+\sum_{j=1}^{5} \beta_{j} X_{i j}+\sum_{j=1}^{5} \sum_{k=1}^{5} \beta_{j k} X_{i j} X_{i k}+\left(\varnothing_{i}-\eta_{i}\right)$

$Y_{i}$ is the quantity of millet harvested by household $i, X_{i 1}$ stands for chemical fertilizers, $X_{i 2}$ for manure, $X_{i 3}$ for labor, $X_{i 4}$ for total land area devoted to millet farming. $\beta_{0}, \beta_{i j}$ are parameters to be estimated, ${ }_{i}$ the error term and $\eta_{i}$ the technical inefficiency component. Factors explaining technical inefficiency are expressed as follows:

$\ln \eta_{i}=\delta_{0}+\sum_{j=1}^{10} \delta_{j} z_{i j}+W_{i}$

$z_{i j}$ is a vector of 10 variables: age, gender, formal education, dependency ratio, off farm income, breeding income, distance to nearest market, access to the village, received transfers, and access to credit. $\delta_{0}, \delta_{j}$, are parameters to be estimated and $W_{i}$ is the error term.

Diagnostic Analysis: To draw consistent conclusions, appropriate specifications are crucial in SFA analysis. It is thus useful to prove that the translog specification of the production function is suitable and that there is a technical inefficiency in millet production before showing that explanatory variables significantly affect this inefficiency. The following hypotheses are tested:

- The Translog production function is more suitable than the Cobb-Douglas production function Under the null hypothesis $\mathrm{H}_{01}$, the Cobb-Douglas function is more appropriate:

$\mathrm{H}_{01}: \beta_{22}=\beta_{33}=\beta_{44}=\beta_{12}=\beta_{13}=\beta_{14}=\beta_{23}=\beta_{24}=\beta_{34}=0$

- There is an inefficiency in cereal production $(\gamma \neq 0)$

Under the null hypothesis $\mathrm{H}_{02}: \gamma=0$ meaning absence of any inefficiency in millet farming. In this case, an ordinary production function is used and estimated by Ordinary Least Squares (OLS).

- Variables used in the model globally explain the technical inefficiency

Under the null hypothesis $\mathrm{H}_{03}$, no variable explains the technical inefficiency:

$\delta_{1}=\delta_{2}=\cdots=\delta_{10}=0$

The three tests are operated by computing the generalized likelihood ratio:

$\lambda=-2 *\left\{\ln \left[\mathrm{L}\left(\mathrm{H}_{0}\right)\right]-\ln \left[\mathrm{L}\left(\mathrm{H}_{1}\right)\right]\right\}$. $\left[\mathrm{L}\left(\mathrm{H}_{0}\right)\right]$ and $\left[\mathrm{L}\left(\mathrm{H}_{1}\right)\right]$ are respectively values of the likelihood function under the null hypothesis $\mathrm{H}_{0}$ and under the alternative hypothesis $\mathrm{H}_{1} . \lambda$ is a Khi Two mix distribution.

Elasticities and Returns to Scale: Elasticities measure the sensitivity of production to changes in input. In the translog stochastic production function, elasticities are expressed as:

$e_{j}=\frac{\partial \ln Y_{i}}{\partial \ln X_{i j}}=\beta_{j}+2 \beta_{j j} \bar{X}_{i j}+\sum_{k \neq j} \beta_{j k} \bar{X}_{i k}$

The returns to scale $(R S)$ measure the sensitivity of the level of production to proportional variations in all inputs. $R S$ is computed by summing the $e_{j}: R S=e_{1}+e_{2}+e_{3}+e_{4}$ 
If $R S=1$, the returns to scale are constant; if $R S<1$, the returns to scale are decreasing and if $R S>1$, the returns to scale are increasing.

Data: The data used in this paper are extracted from a survey data collected in 2017 for evaluating the "National community based Program, Phase II (PNGT2)". The program PNGT2 was launched in 2013 to contribute to an increase in productivity, added values and agricultural income with a view to contributing to national economic growth and poverty reduction. The survey was thus carried out by a national laboratory (LAQADS ${ }^{1}$ ) in order to contribute to the apprehension of households living conditions in rural areas. Data collected on 2160 households randomly selected cover all regions of the country and include household's demographic characteristics and living conditions, soil characteristics, agricultural and livestock production etc. A total of 224 households have been surveyed in the Sahel region in 2017 by the LAQADS. Among those households, 106 are millet farmers. The sample in this analysis is all the 106 households in the data set who are engaged in millet farming in this region. Table 1 describes variables used for the empirical analysis. It shows that households are mostly headed by men (95.25 \%) and few have received formal education (16.03 $\%)$. In the study area, households are also characterized by a high dependency ratio (52.97\%).

Table 1: Description, Mean and Standard Deviation of the Variables Used for the Empirical Analysis

\begin{tabular}{|c|c|c|c|c|}
\hline \multicolumn{2}{|l|}{ Variable } & $\begin{array}{l}\text { Description } \\
\text { Dependent variable }\end{array}$ & Mean & $\begin{array}{l}\text { Standard } \\
\text { Deviation }\end{array}$ \\
\hline \multirow[t]{2}{*}{ Output } & $\mathrm{Y}$ & Quantity of millet harvested $(\mathrm{kg})$ & 587.49 & 1192.35 \\
\hline & & Production Function Variables & & \\
\hline Fertilizers & $X_{1}$ & Quantity of chemical fertilizers used in millet farming (kg) & 11.90 & 23.009 \\
\hline Manure & $X_{2}$ & $\begin{array}{l}\text { Number of cartloads equivalent of manure used in millet } \\
\text { farming }\end{array}$ & 4.44 & 8.31 \\
\hline Labor & $X_{3}$ & Quantity of labor used in millet farming (man-days) & 108.04 & 142.96 \\
\hline Area & $X_{4}$ & $\begin{array}{l}\text { Total area devoted to millet farming (ha) } \\
\text { Determinants of Technical Inefficiency }\end{array}$ & 1.576 & 1.64 \\
\hline \multicolumn{2}{|l|}{ Age } & Age of the household head (number of years) & 49.80 & 15.21 \\
\hline \multicolumn{2}{|l|}{ Gender } & 1 if the household head is male and 0 otherwise & 0.9528 & 0.213 \\
\hline \multicolumn{2}{|l|}{ Education } & $\begin{array}{l}1 \text { if the household head has received formal education and } 0 \\
\text { otherwise }\end{array}$ & 0.16037 & 0.3686 \\
\hline \multicolumn{2}{|c|}{ Dependency ratio } & Ratio of the household non active members & 0.5297 & 0.1718 \\
\hline \multicolumn{2}{|c|}{ Breeding income } & income-generated from breeding (FCFA) & 228298.3 & 550065.8 \\
\hline \multicolumn{2}{|c|}{ Off farm income } & income-generated from off farm activities (FCFA) & 257418 & 2,320000 \\
\hline \multicolumn{2}{|c|}{ Distance } & Distance to the nearest market $(\mathrm{km})$ & 20.77 & 26.32 \\
\hline \multicolumn{2}{|l|}{ Good access } & $\begin{array}{l}1 \text { if the farmer living area is accessible in rainy season and } 0 \\
\text { otherwise }\end{array}$ & 0.51886 & 0.5020 \\
\hline \multicolumn{2}{|l|}{ Transfer } & 1 if the household received extra household cash transfer & 0.8207 & 0.3853 \\
\hline \multicolumn{2}{|c|}{ Access to credit } & $\begin{array}{l}1 \text { if household's members have access to credit and } 0 \\
\text { otherwise }\end{array}$ & 0.3679 & 0.4845 \\
\hline
\end{tabular}

Source: Author' construction from data PNGT2 2017.

\section{Results and Discussion}

Diagnostic Test Results: Table 2 presents hypothesis test results. The likelihood ratio $(\lambda=1,029.62)$ calculated in testing hypothesis $\mathrm{H}_{01}$ is significant $(\mathrm{P}=0.000)$. The translog specification is more suitable than

\footnotetext{
${ }^{1}$ A research Laboratory, specialized in household data collection and quantitative analysis, University Ouaga II
} 
the Cobb-Douglass one. The value of the likelihood ratio computed from the estimation of the translog production function by the OLS and by the maximum likelihood method is $\lambda=329.46$. This Value is significant at $1 \%$ level $(\mathrm{P}=0.0000)$ and the null hypothesis is not accepted. The conclusion is that there is a technical inefficiency in cereal production. Similarly, the ratio $\lambda=4,356.21$ generated in the third hypothesis test is significant at $1 \%$ level $(\mathrm{p}=0.0000)$. The null hypothesis is not accepted implying that the variables used globally explain the technical inefficiency. Based on the diagnostic test results, it is can be concluded that the results are very consistent.

Table 2: Validation of Hypotheses

\begin{tabular}{|c|c|c|}
\hline Null hypothesis & $\begin{array}{l}\text { Statistics } \\
\text { (Probability) }\end{array}$ & Decision \\
\hline $\mathrm{H}_{01}: \boldsymbol{\beta}_{j k}=\mathbf{0}$ & $1,029.62^{* * *}$ & $\mathrm{H}_{01}$ rejected \\
\hline $\begin{array}{l}\text { The translog function can be reduced to a Cobb- } \\
\text { Douglass one }\end{array}$ & $(0.0000)$ & \\
\hline $\mathrm{H}_{02}: \boldsymbol{\gamma}=\mathbf{0}$ & $329.46^{* * *}$ & $\mathrm{H}_{02}$ rejected \\
\hline $\begin{array}{l}\text { There is no technical inefficiency in millet production } \\
\mathbf{H}_{\mathbf{0} 3}: \boldsymbol{\delta}_{\mathbf{1}}=\boldsymbol{\delta}_{\mathbf{2}}=\cdots=\boldsymbol{\delta}_{\mathbf{1 0}}=\mathbf{0} \\
\text { No variable explains the technical inefficiency }\end{array}$ & $\begin{array}{l}(0.0000) \\
4,356.21^{* * *} \\
(0.0000)\end{array}$ & $\mathrm{H}_{03}$ rejected \\
\hline
\end{tabular}

Source: Author construction from data PNGT2 2017

*** $1 \%$ significant

The Level of Technical Efficiency of Millet Farmers: Table 3 classifies households according to their level of technical efficiency. The mean technical efficiency is estimated at $71.23 \%$. The level of technical efficiency is ranged from $5.94 \%$ to $92.19 \%$ across households. These statistics show that farmers are operating under their potential production level. They may increase their production by $28.77 \%$ with the same resources. The factors inducing such inefficiency must be addressed to increase millet productivity in the region.

Table 3: Frequency Distribution of Technical Efficiency of the Millet Farmers

\begin{tabular}{lll}
\hline Level of Efficiency (\%) & Number of Households & Percentage of Households \\
\hline $0-25$ & 7 & 6.60 \\
$25-50$ & 5 & 4.71 \\
$50-75$ & 37 & 34.91
\end{tabular}

$\begin{array}{lll}75-100 & 57 & 53.78\end{array}$

Mean technical efficiency $=71.23 \%$

Minimum technical efficiency $=5.94 \%$

Maximum technical efficiency $=92.19 \%$

Source: Author construction from data PNGT2 2017

Maximum Likelihood Estimates of the Production Function: Table 4 presents the estimates of the translog production function. All inputs factors positively and significantly affect the quantity of millet harvested by the households. The use of chemical fertilizers and manure by farmers is so crucial because soils are generally of poor quality in the Sahel region. Fertilizers use is thus recommended to endow soils with necessary nutrients for millet growth. The positive correlation between land area and output level is suitable to Burkina Faso context where producers tend to increase their output by extensification (Callo-Concha et al., 2012). Similar results are found by Jayakody \& Dishanka in Sri Lanka and by Aduba et al. (2013) in Nigeria where fertilizers and land area are the major factors explaining the production level. Labor has also a positive effect on production. Due to poor production technologies adopted by farmers, labor is hugely needed for an appropriate farm management especially for weeding. Households' members have to spend most of their time on their farms during the rainy season. 
The Determinants of Technical Efficiency: The results of the determinants of technical inefficiency are presented at the bottom of table 4 . A total of four (4) variables significantly affect millet production efficiency in the Sahel region: formal education, breeding income, access to credit and good access to farmers' living area in rainy season. The results of formal education are consistent with the human capital predictions. Households headed by farmers who have received formal education are expected to use resources more efficiently as it is argued that those farmers are opened to best agricultural practices and rationally manage their farms (Becker, 1993). Our findings are similar to the results found by Agboola (2016) for Nigeria, and Alene \& Hassan (2003) for Ethiopia. The lack of financial resources is one of the major constraints to agricultural development in countries such as Burkina Faso. Most farmers need financial support to purchase agricultural inputs in due time and to efficiently manage their farm activities. Indeed, Provision of credit enhanced timely purchase and efficient allocation of factor inputs to produce the maximum output.

Kuwornu et al. (2013) found that credit access is among major factors determining the technical efficiency level of maize farmers in Ghana. Access to credit is therefore very important to farmers' production decisions. Most farmers however lack collateral and are constrained in the formal credit market in Burkina Faso. Regarding income generated from breeding, Pender et al. (2002), argued that farmers in developing countries lie on livestock as an alternative to solving credit constraint. Especially in the Sahel region of Burkina Faso, breeding is an important activity for households. The climate of this area of the country is adapted to this activity and farmers use breeding to sustain their agriculture. Combining breeding to farming may thus be an important way of stimulating farmers' productivity. The results also show that good road infrastructure is a key factor in stimulating production efficiency. Farmers located in areas with good roads access in rainy season are more likely to better manage their farms as they are able to get access to both market and extensions services located at communal level.

On the contrary, farmers located in inaccessible zones in rainy season are constrained to market access which hampers their production performances. Road infrastructure improvement can be expected to raise the output price of the farmers and lower production cost through the reduced transportation cost of goods and services (Kiprono \& Matsumoto, 2014). In the Sahel region, road infrastructures are however poor and this may hamper millet production.

Table 4: The Translog Frontier Production Function Estimates and the Determinants of Technical Efficiency

\begin{tabular}{|c|c|}
\hline Variables & $\begin{array}{c}\text { Translog Production Function Estimates } \\
\text { Coefficient }\end{array}$ \\
\hline
\end{tabular}

\begin{tabular}{|c|c|c|c|}
\hline Constant & $\mathrm{C}$ & 3.884 & 0.03 \\
\hline Chemical fertilizers & $\ln X_{1}$ & $0.5368^{* * *}$ & 3.19 \\
\hline Manure & $\ln X_{2}$ & $0.5805^{* *}$ & -2.18 \\
\hline Labor & $\ln X_{3}$ & $0.7903^{* * *}$ & 4.86 \\
\hline \multirow[t]{11}{*}{ Total millet area } & $\ln X_{4}$ & $1.184^{* * *}$ & 4.05 \\
\hline & $\ln X_{1}^{2}$ & 0.0588 & 1.08 \\
\hline & $\ln X_{2}^{2}$ & 0.1034 & 1.22 \\
\hline & $\ln X_{3}^{2}$ & $-0.0263^{* *}$ & -1.98 \\
\hline & $\ln X_{4}^{2}$ & -0.0370 & 1.09 \\
\hline & $\ln X_{1} \ln X_{2}$ & $0.1008^{* *}$ & 2.04 \\
\hline & $\ln X_{1} \ln X_{3}$ & $-0.1764^{* * *}$ & -2.64 \\
\hline & $\ln X_{1} \ln X_{4}$ & 0.0781 & 0.98 \\
\hline & $\ln X_{2} \ln X_{3}$ & 0.0581 & 0.55 \\
\hline & $\ln X_{2} \ln X_{4}$ & -0.0203 & -0.17 \\
\hline & $\ln X_{3} \ln X_{4}$ & 0.0592 & 1.58 \\
\hline
\end{tabular}

\section{Determinants of Technical Inefficiency in Millet Farming}

Constant

Age of household head $\quad-0.0037 \quad-0.74$

Gender of household head

$-0.2259$

$-0.59$ 


\begin{tabular}{|c|c|c|}
\hline Formal education of household head & $-0.5328^{* * *}$ & -3.00 \\
\hline Dependency ratio & 0.5180 & 1.02 \\
\hline Off farm income & 0.0109 & 0.85 \\
\hline Breeding income & $-0.0342 *$ & -1.64 \\
\hline Distance to the nearest market & 0.0002 & 0.07 \\
\hline Good access to the village & $-0.5679 * * *$ & -2.89 \\
\hline Received transfers & -0.0937 & -0.51 \\
\hline Access to credit & $-0.3696^{* *}$ & -2.24 \\
\hline$\sigma^{2}$ & 4.0882 & \\
\hline$\gamma$ & 0.90050 & \\
\hline Mean Technical Efficiency & $71.23 \%$ & \\
\hline & Chi2 $(20)=2058.62^{* * *}$ & \\
\hline
\end{tabular}

Number of Observations $=106$

Source: Author estimation from data PNGT2 2017

*** $1 \%$ significant; ** $\%$ significant; $* 10 \%$ significant

Elasticities and Returns to Scale: The elasticities are presented in table 5. Millet production is sensitive to the four inputs resource variables. An increase of $1 \%$ in the total area and labor leads respectively to an increase of $0.504 \%$ and $0.008 \%$ in millet production while an increase of $1 \%$ in chemical fertilizers and manure leads to an increase of $0.410 \%$ and $0.57 \%$ in millet production respectively. The computed value of the returns to scale by summing the elasticities is 1.49 . This value which is greater than the unit indicates that the returns to scale are increasing. A simultaneous increase in expenditure on chemical fertilizers, manure, labor and farm area by $1 \%$ results in an increase of $1.49 \%$ in millet production. This reflects a situation where the increase in the scale of production is profitable for producers. Millet farmers in the Sahel region must be encouraged to increase their scale of production in order to generate more agricultural income.

Table 5: Elasticities of Resources

\begin{tabular}{lll}
\hline Input Resource & Elasticity & Probability \\
\hline Chemical fertilizers & $0.4102^{* * *}$ & 0.0000 \\
Manure & $0.5728^{* * *}$ & 0.000 \\
Labor & $0.0083^{* *}$ & 0.041 \\
Total area & $0.5043^{* * *}$ & 0.0000 \\
Returns to Scale (RS) $=\mathbf{1 . 4 9}$ & &
\end{tabular}

Source: Author computing from results

** $5 \%$ significant; ${ }^{* * *} 1 \%$ significant

\section{Conclusion and Policy Recommendations}

Millet is the main cereal crop assuring the food security of rural households in the Sahel region of Burkina Faso. This study was carried out to analyze factors affecting the technical efficiency of millet production in this region. A stochastic frontier approach has been followed with a one-step estimation method leading to consistent results. The results show that farmers in the Sahel region are technically inefficient in millet farming. The mean technical efficiency is estimated at $71.23 \%$ implying that households have the possibility of increasing their production by $28.77 \%$ without resorting to an increase of their resources devoted to millet production. The results show that formal education, breeding, access to credit and good road infrastructure is the key factors affecting the millet production efficiency in the region. The study recommends decisions makers to take appropriate measures to enhance production in this region in order to improve rural people food security.

From our findings, it is observed that a low proportion of millet farmers attended formal education. At a short run, farmers need to be trained on how to efficiently manage their farms. At a long run, all policies aiming at increasing the level of school attendance in the zone have to be supported. In this way, the problem of civil 
insecurity which hampers schools attendance has to be solved. The government should also improve road infrastructures in the region in order to facilitate farmers' access to market and extensions agents who are generally located at communal level. Also, the development of microfinance with the support of the government in the region may reduce credit constraint and stimulate production. As most of the farmers have no collateral, they must be well organized to get credit through group membership. Finally, farmers may be trained to integrated farm management combining agriculture and breeding. This may stimulate their production efficiency and improve rural households' food security in the Sahel region.

\section{References}

Aduba, J. J., Oladunni, O. A. \& Onojah, D. (2013). Technical Efficiency of Smallholder Maize Farmers in Nigeria: The Stochastic Frontier Approach. Global Journal of Current Research, 1(14), 132-140.

Agboola, W. L. (2016). Land Management Practices and Technical Efficiency of Food Crop Farmers in North Central Nigeria: A Data Envelopment Analysis (DEA) Approach. Asian Journal of Agricultural Extension, Economics \& Sociology, 10(2), 1-10.

Aigner, D., Lovell, C. A. K. \& Schmidt, P. (1977). Formulation and estimation of stochastic frontier production models. Journal of Econometrics, 6(1), 21-37.

Alene, A. D. \& Hassan, R. M. (2003). The determinants of farm-level technical efficiency among adopters of improved maize production technology in western Ethiopia. Agrekon, 42(1), 1-14.

Becker, G. S. (1993). Human Capital. 3rd ed., the university of Chicago Press,Chicago, IL.

Brümmer, B. (2006). Food Policy to alleviate rural poverty: the potential contribution of productivity growth in Agriculture and agricultural trade linearization. Quarterly Journal of international Agriculture, 45(1), 1-6.

Callo-Concha, D., Gaiser, T. \& Ewert, F. (2012). Farming and cropping systems in the West African Sudanian Savanna, WASCAL research area: Northern Ghana, Southwest Burkina Faso and Northern Benin. ZEF Working Paper Series, ISSN 1864-6638, Center for Development Research (ZEF), University of Bonn.

Chavas, J. P., Petrie, R. \& Roth, M. (2005). Farm Household Production Efficiency: Evidence From The Gambia. American Journal of Agricultural Economics, 87(1), 160-179.

Chiona, S., Kalinda, T. \& Tembo, G. (2014). Stochastic Frontier Analysis of the Technical Efficiency of Smallholder Maize Farmers in Central Province, Zambia. Journal of Agricultural Science, 6(10), 108118.

Coelli, T. (1995). Recent developments in frontier modeling and efficiency measurement. Australian Journal of Agricultural Economics, 39(3), 219-45.

Combary, S. O. (2016). Analysing the efficiency of farms in Burkina Faso. African Journal of Agricultural and Resource Economics, 12(3), 242-256.

Coulibaly, A. D. \& Savadogo K. (2019). Does fertiliser subsidy increase maize productivity in Burkina Faso. Development in Practice, DOI: 10.1080/09614524.2019.1670783.

FAO. (2013). Analyse des incitations et pénalisations pour le maïs au Burkina Faso. . Série rapport pays SPAAA, FAO: Rome.

FAO. (2019). Food security situation deteriorating in northern areas due to heightened violence. GIEWS Update, FAO: Rome.

Farrell, M. J. (1957). The Measurement of Productive Efficiency. Journal of the Royal Statistical Society Series A (General), 120(3), 253-290.

Jayakody, S. \& Dishanka, S. (2019). An Estimation of Technical Efficiency of Tea Smallholdings in Ratnapura District of Sri Lanka. Journal of Social and Development Sciences, 10(4), 1-11.

Kaboré, D. P. (2007). Efficience technique de la production rizicole sur les périmètres aménagés du Burkina Faso. Série document de travail DT-CAPES n²007-35, CAPES, Burkina Faso.

Keane, J., Page, S., Kergna, A. \& Kennan, J. (2009). Climate Change and Developing Country Agriculture: An Overview of Expected Impacts, Adaptation and Mitigation Challenges, and Funding Requirements. ICTSD-IPC Platform on Climate Change Agriculture and Trade, International Centre for Trade and Sustainable Development, Geneva, Switzerland and International Food \& Agricultural Trade Policy Council, Washington DC, USA, Issue Brief No.2.

Kiprono, P. \& Matsumoto, T. (2014). Roads and farming: The effect of infrastructure improvement on agricultural input use, farm productivity and market participation in Kenya. In CSAE conference 2014: Economic development in Africa, The University of Oxford. 
Kuwornu, J. K. M., Amoah, E. \& Seini, W. (2013). Technical Efficiency Analysis of Maize Farmers in the Eastern Region of Ghana. Journal of Social and Development Sciences, 4(2), 84-99.

Meeusen, W. \& Van den Broeck, J. (1977). Efficiency Estimation from Cobb-Douglas Production Functions with Composed Error. International Economic Review, 18, 435-444.

Njeru, J. (2010). Factors Influencing Technical Efficiencies among Selected Wheat Farmers in Uasin Gishu District, Kenya. African Economic Research Consortium, Nairobi, Kenya.

Noufé, T. (2020). Agricultural productivity and poverty of agricultural households in Burkina Faso. African Journal of Economic and Sustainable Development, 7(4), 287-306.

Ogundaria, K. \& Awokuse T. (2016). Land Tenure and Technical Efficiency of Rice Farms in Thailand. . Paper presented at 2016 World Bank Conference on Land and Poverty, The World Bank - Washington DC.

Pender, J. L., Nonya, E., Jagger, P. \& Serunkuuma, D. (2002). Strategies to increase agricultural productivity and reduce land degradation: evidence from Uganda. Paper presented at the Worshop on Methodological Advances for Assessing Impacts of NRM Research. 6-7 december, ICRISAT, Pantancheru, India.

Thiam, A., Bravo-Ureta, B. E. \& Rivas, T. (2001). Technical efficiency in developing country agriculture: a meta-analysis. Agricultural Economics, 25, 235-243.

Wouterse, F. (2008). Migration and Technical Efficiency in Cereal Production: Evidence from Burkina Faso. IFPRI, Dakar, Senegal. 